\title{
Distinct Emotions, Distinct Domains: Anger, Anxiety and Perceptions of Intentionality
}

\author{
Michael Bang Petersen Aarhus University
}

\begin{abstract}
Drawing on recent work in evolutionary psychology, anxiety and anger are argued to be distinct emotions operating in the domains of hazards and morality, respectively. Based on this distinction, it is predicted and demonstrated that the effect of anger on criminal justice opinions (and another moral emotion: compassion) is conditioned by perceptions of the intentions of criminals, while the effect of anxiety is unrelated to these perceptions. These results demonstrate that it is fruitful to distinguish emotions beyond their valence.
\end{abstract}

$\mathrm{E}$ motions have become central to the study of public opinion (for introductions, see Marcus, Neuman, and MacKuen 2000; Neuman et al. 2007; Redlawsk 2006). When new concepts gain prominence, discussions about the proper level of conceptualization become inevitable. However, political research on emotions rapidly converged on a particular conceptualization of emotions. Hence, the dominant model in both earlier and current work has been to focus on the valence of citizen's emotional experience, i.e., whether emotions are of a positive or negative nature (e.g., Brader, Valentino, and Suhay 2008; Kuklinski et al. 1991; Lodge and Taber 2005; Marcus, Neuman, and MacKuen 2000; Sniderman, Brody, and Tetlock 1991). From this perspective, researchers have indeed uncovered important findings on how the emotional states of citizens shape their political thinking, e.g., by demonstrating how positive emotions such as enthusiasm temper the ability of voters to critically scrutinize political information, while negative emotions such as anxiety facilitate higher levels of information processing (Marcus, Neuman, and MacKuen 2000).

Nevertheless, valence-oriented models of emotions can be viewed as overly simplistic. Hence, a long line of research in psychology has demonstrated that the dimensions of positive and negative emotions consist of multiple distinct emotions with distinct triggers and effects (for introductions, see Ellsworth and Scherer 2003; Lazarus 1991). Building on these insights, a handful of recent studies in political science have demonstrated how the activation of two neg- ative emotions-anger and anxiety-have profoundly different political implications (Druckman and McDermott 2008; Huddy, Feldman, and Cassese 2007; Marcus et al. 2006; Redlawsk et al. 2007; Steenbergen and Ellis 2006). For example, Huddy, Feldman, and Cassese (2007) investigate anxiety and anger as predictors of opinions on the war in Iraq, demonstrating that while anxiety reduces support for the war, feelings of anger toward Saddam Hussein increase support for the war. Similarly, Druckman and McDermott (2008) show that while anxiety reduces the support for risky policies, anger increases the support for such policies.

Still, no current consensus exists as to whether political scientists must differentiate between anger and anxiety. Hence, other studies have documented that experiences of anger and anxiety are very closely related (for a thorough discussion, see Marcus, Neuman, and MacKuen 2000); have argued that anger and anxiety are only sometimes distinct (Marcus et al. 2006); or have even failed to find any differences in the effects of anger and anxiety (Brader, Valentino, and Suhay 2008). This state of affairs is presumably sustained by the fact that most of the recent studies - or the psychological work upon which they build (e.g., Ellsworth and Smith 1988; Smith and Ellsworth 1985)—have been data driven and, hence, have not offered a deep understanding of why emotions such as anger and anxiety could operate in distinct ways.

In this article, the potential distinctiveness of anger and anxiety is explored in greater detail, and novel evidence for the fruitfulness of distinguishing 
emotions beyond their valence is provided. Utilizing research in evolutionary psychology on emotions (Ermer et al. 2006; Fiddick 2004), it is argued that anxiety and anger are not only distinct but also operate in distinct domains of political life. Consistent with the dominant approach to negative emotions in political science, Affective Intelligence Theory, anxiety is argued to regulate behavior and opinions in the face of hazards, i.e., everything from terrorist attacks to rising unemployment rates and environmental disasters. Anger, however, is argued to form part of a distinct collection of moral emotions, which specifically regulate behavior and opinions towards people (Haidt 2003), i.e., political candidates or salient target groups such as welfare recipients, criminals, and immigrants. Evolutionary analyses and evidence from neuroscience suggest that a key difference between the domains of hazards and morality relates to the importance of intentionality (Ermer et al. 2006; Fiddick 2004). In the domain of hazards, precautions must be taken regardless of whether intentionality is involved. Conversely, intentionality is particularly important in the social domain for whether we express moral blame or praise.

Empirically, anxiety is contrasted with anger and another moral emotion: compassion. Focusing on criminal justice opinions, analyses of a large-scale survey demonstrate that perceptions of the intentions of criminals condition the extent to which criminal justice opinions are based on anger and compassion. In contrast, as predicted, the effect of anxiety is unrelated to perceptions of criminal intent. These findings not only suggest that it is fruitful to distinguish emotions beyond their valence; as discussed in the concluding section, they also suggest that emotion research increasingly ought to consider the importance of moral intuitions, carry implications for political elites' use of emotional appeals, and suggest how evolutionary psychology can inform political research.

\section{Anxiety, Anger, and the Role of Intentions}

According to Affective Intelligence Theory, feelings of anxiety are the output of a surveillance system designed to "scan the environment for novelty and sudden intrusion of threat" (Marcus, Neuman, and MacKuen $2000,10)$ and motivate one to take the necessary precautions. One such effect of anxiety is the suspension of current habits and increased information processing. In politics, this causes anxious voters to rely less on their party identification and more on issue-specific preferences in their vote choice and to search for and remember more political information during elections. Affective Intelligence Theory generally treats all negative emotions, including anger, as part of this precautionary behavior-inhibition system (cf. Marcus, Neuman, and MacKuen 2000). More recently, however, research in this tradition has opened up to the possibility that anger might be treated as distinct (e.g., Marcus 2002; Marcus et al. 2006). Even if distinct from anxiety, however, anger is still believed to regulate the expression of habits in the face of threat. ${ }^{1}$

To discern between anger and anxiety in greater detail, I turn towards research in evolutionary psychology. Evolutionary psychologists analyze emotions as functional products of biological evolution (Barkow, Cosmides, and Tooby 1992), and a long line of studies in evolutionary psychology has focused on the potential differences between the psychologies of anger and anxiety (for an overview, see Cosmides and Tooby 2005). Consistent with Affective Intelligence Theory, evolutionary psychologists argue that feelings of anxiety and fear are related to the activation of precautionary reasoning and designed as part of a general system to manage hazards (see, e.g, Boyer and Liénard 2006; Fiddick 2004). Evolutionary psychologists, however, treat anger as belonging to a distinct collection of moral emotions specifically designed to pass moral judgment on people (Haidt 2003; Fiddick 2004). ${ }^{2}$ In this perspective, anger is designed to manage social rule violations, and the elicitation of anger leads to expressions of blame and support for punishment of rule violators (for a detailed evolutionary dissection of anger, see Tooby et al. 2008).

One significant difference between the domain of hazards and the domain of morality and rule violation relates to the importance of intentionality (Ermer et al. 2006; Fiddick 2004). In the evolutionary perspective, anger evolved to manage rule violations in ancestral small-scale groups with high levels of social dependence between the members (Cosmides and Tooby 2005). Simulations of evolutionary processes suggest

\footnotetext{
${ }^{1}$ Specifically, Affective Intelligence Theory suggests that anger (or "aversion," as it is labelled) is triggered in the face of recurrent threats, while anxiety is believed to be triggered in the face of novel threats. Upon activation, anger is expected to reinforce rather than suspend habits (Marcus 2002; Marcus et al. 2006).

${ }^{2}$ Haidt (2003) identifies 10 moral emotions separated into four emotion families: (1) the other-condemning emotions: anger, contempt, and disgust; (2) the self-conscious emotions: shame, embarrassment, and guilt; (3) the other-suffering emotions: compassion; and (4) the other-praising emotions: gratitude, awe, and elevation.
} 
that this environment selected for certain functional restraints on the activation of anger, because unnecessary aggression would disrupt otherwise valuable relationships (see e.g., Axelrod 1984; de Waal 1996; Petersen et al. 2010). Anger is therefore only expected to be triggered in the face of intentional rule violations (Cosmides and Tooby 2005). Contrastingly, accidental or involuntary violations are believed to activate another moral emotion-compassionwhich facilitates conciliatory responses (Haidt, 2003; Petersen et al. 2010). A range of neuroscience studies have provided evidence for this role of intentions in the moral domain by comparing how subjects react to economic outcomes attributable to (1) random decisions by a computer and (2) intentional decisions by another subject (for an overview, see Petersen, Roepstorff, and Serritzlew 2009). These studies document that only bad outcomes attributable to human intentional agency activate brain circuits related to anger (e.g., de Quervain et al. 2004; Sanfey et al. 2003).

While intentions matter in the moral domain, hazards are dangerous whether or not intentionality is involved. Therefore, we have presumably evolved to take the necessary protective measures whenever danger arises independently of whether or not this danger relates to intentional behavior (Ermer et al. 2006; Fiddick 2004). Consistent with this argument, a recent neuroscience study demonstrates that while the detection of social rule violations activate the brain areas involved in intention reading (the anterior and posterior temporal cortex), the detection of hazards does not (Ermer et al. 2006).

According to neuroscientist Antonio Damasio, we can conceive of emotions as "locks that only open if the appropriate key fits" $(2003,58)$. The above arguments lead us to expect that anger and anxiety are distinct emotions and, in particular, that perceptions of intent fit the trigger conditions of these two emotional systems to varying degrees. While anger and anxiety are both negatively valenced, perceptions of intentionality are expected to regulate feelings of anger but not feelings of anxiety. These arguments also allow us to further substantiate the claim that emotions must be distinguished beyond valence. Hence, while anger and compassion have different valences, perceptions of intentionality should matter for both moral emotions.

\section{Hypotheses on Criminal Justice}

A recent study has provided some initial evidence for these predictions in the field of politics. Hence, in a study of framing and criminal justice, Gross (2008) found that more vivid descriptions of criminals triggered more anger and more compassionate reactions, but not more anxiety. To test the predictions in detail, I follow Gross and focus on the issue of criminal justice. Criminal justice has two important features: First, crime is both a hazard and a rule violation. Second, it is an issue with a particularly salient target group (criminals). Hence, perceptions of intentionality and related emotions can be expected to influence opinions strongly. In line with this, prior research in criminal justice has shown that criminal justice opinions are indeed influenced by feelings of anger, compassion and anxiety (Gault and Sabini 2000; Sprott and Doob 1997) together with perceptions of the intentionality of criminals (Cullen et al. 1985; Iyengar 1991), yet no studies have focused on the interplay between these cognitions and emotions.

Before outlining the specific predictions, it is necessary to note the difficulties associated with analyzing emotions and cognitions. As argued by Huddy, Feldman, and Cassese, "cognitions and emotions operate in a recursive loop in which cognitions influence emotions which influence cognitions, in turn-making it difficult to know whether cognitive appraisals are a cause or consequence of differing emotional states" (2007, 210; see also, Keltner, Ellsworth, and Edwards 1993; Niedenthal and Setterlund 1994). In other words, emotions and cognitions co-occur. Given this, the empirical objective becomes using interactive modeling to demonstrate that the effects of anger and compassion, but not anxiety, on criminal justice opinions co-occur with unambiguous perceptions of the intentions and motivations of criminals.

Given the proposed structure of the anger system, individuals who unambiguously perceive criminals as highly intentional can be expected to feel high levels of anger and be in favor of severe punishments, whereas individuals who unambiguously perceive criminals as unintentional wrongdoers should feel low levels of anger and be opposed to punishment. Hence, among individuals with unambiguous perceptions regarding criminal intent, we should expect a strong relationship between their felt level of anger and their attitudes to criminal justice. The first prediction, the anger-interaction hypothesis, thus posits that the effect of anger on criminal justice opinions is conditioned by the extent to which citizens have explicit perceptions regarding criminals' intentions. Similarly, the compassion-interaction hypothesis posits that the effect of compassion on opinions regarding criminal justice is conditioned by the extent to which citizens have explicit perceptions 
about the intentions of criminals (in contrast to anger, however, compassion is expected to lead to less punitive attitudes).

Given the proposed distinction between anxiety and anger and compassion, contrasting expectations pertain to anxiety. Hence, anxious individuals ought to perceive crime as a hazard and be motivated to take the precautions necessary (e.g., lock wrongdoers away), no matter how they believe criminals to be motivated. Thus, the anxiety-no-interaction hypothesis posits that there is no interaction effect between the effect of anxiety on citizens' criminal justice opinion and the ambiguity of their perceptions of the intentions of criminals.

These hypotheses are far from trivial. In particular, the contrast proposed between anger and anxiety moves beyond the current knowledge in political science as well as psychology. ${ }^{3}$ Furthermore, current knowledge seems to be biased against the hypotheses. Hence, studies have demonstrated the existence of a relationship between an individual's proneness to experience anxiety and their degree of conservatism (Oxley et al. 2008). Given the relationship between conservatism and attributions of high levels of intentionality (Zucker and Weiner 1993), this would, ceteris paribus, imply that proneness to experience anxiety is linked to these perceptions. The anxiety-no-interaction hypothesis suggests otherwise.

\section{Study Design}

The data used to test the argument is taken from a large-scale $(\mathrm{N}=4116)$ paper-and-pencil survey about criminal justice opinions conducted in Denmark from

\footnotetext{
${ }^{3}$ In relation to anxiety and fear, the psychological literature on discrete emotions and their antecedent appraisals have only explored appraisal dimensions that map the dimension of intentionality in unclear ways (such as whether an outcome is attributable to oneself or another or whether an outcome is attributable to environmental or human factors). Consistent with the perspective developed here, studies have shown that fear and anxiety are often triggered in negative situations beyond human control (i.e., nonhuman hazards; Ellsworth \& Smith, 1985), but they have not addressed whether feelings of anxiety are regulated by perceptions of intentionality when the negative situation is in fact caused by the actions of con-specifics (as is the case with crime; cf. Smith et al., 1993, 917). Outside politics, the appraisal literature has provided evidence that feelings of anger and compassion are related to perceptions of intentionality (Weiner, 1991). Still, the question remains whether this relationship travels directly and unproblematically to the realm of politics. In this regard, it should also be noted that the appraisal literature explicitly proceeds from the premise that "emotions [are] adaptive products of our evolution" (Ellsworth and Smith, 1988, 299). Hence, the findings of this literature corroborate rather than challenge the theoretical perspectives developed in the present article.
}

January to March 2005. The respondents were students at 45 different upper-secondary educational institutions (high schools, business schools, and vocational schools). The schools were from different areas of the country and had different ethnic compositions and degrees of urbanization. The respondents are between 15 and 21 years of age and come from a wide range of different social backgrounds (approximately $85 \%$ of all Danish youth complete an upper secondary education).

First of all, we need a measure of the respondents' opinions in relation to criminal justice issues. This measure is created by tallying the answers to five 5 -point Likert-scaled items. The claims involved are the following: "Criminals deserve to be punished, because they have caused damage"; "Punishment will teach the criminal to behave properly"; "No matter the circumstances of the crime, it is always morally correct to punish criminals harshly"; "We ought to help criminals become good citizens again" (reversed); and "We should try to help criminals realize that they cause harm" (reversed). A high value on this scale indicates support for punishment.

The emotional experiences of anger, compassion, and anxiety are measured using three 5-point Likertscales. The item measuring anger is "I often get angry at those who commit crimes", while the item used to measure compassion is "I often feel sorry for criminals." Finally, the following item measures anxiety: "I often worry that I will fall victim to crime."

To test the predicted interaction effects, a measure is needed that directly taps the explicitness of the perceptions of the intentionality of criminals. Steenbergen and Brewer's (2004) revised Griffin formula is used to this end, designed as it is to measure the conflict between values on rating scales. The first scale is constructed based on the following two 5-point Likert-scale items: "Most criminals commit crimes because they know they can get away with it" and "Most criminals are psychopaths who do not care about others at all." The second scale is constructed using two other items: "Deep down, many criminals are regular people like you and me" and "Criminals are victims of a hard upbringing." Hence, a high value on the first scale indicates that criminals are conceived as intentional offenders who are likely to commit crime again in the future, while a high value on the second scale indicates that criminals are seen as reformable persons under the influence of external forces. Based on the revised Griffin formula, a measure of the consistency between a respondent's values on these scales is computed. Respondents placed on the low extreme of this final measure have highly mixed and incoherent perceptions 
about the motives of criminals, while the perceptions of the respondents at the high extreme of the scale unambiguously either stress the bad intentions of criminal intentions or the lack hereof. ${ }^{4}$

Finally, three demographic variables are used as controls: gender, age, and education (high school versus non-high school). All measures have been rescaled to vary from 0 to 1 .

\section{Empirical Results}

The empirical results are presented in Table 1, where the different explanatory factors and controls are regressed on the criminal justice opinion. Before testing the interactive hypotheses, the additive effects of perceptions and emotions are investigated. Specifically, Model 1 includes the control variables and additive effects of the emotional measures. In line with previous studies, females (Gault and Sabini 2000) and the higher educated (Stubager 2008) are less punitive. Furthermore, supporting the argument presented here, the significant effects of emotions in Model 1 imply that criminal justice opinions are indeed infused with emotions. Differences in anger and compassion in particular cause attitudinal differences: Anger increases support for punishment, while compassion towards criminals reduces the support for punishment. Anxiety also significantly increases the support for punishment, although the effect is smaller. Hence, statecentered punitive policies both satisfy angry and anxious individuals by imposing costs on offenders as well as providing protection for citizens.

Model 2 in Table 1 introduces the measure of whether the respondents hold unambiguous perceptions of the intentions of criminals and the crucial interaction terms between this measure and the experience of anger, compassion, and anxiety, respectively. It should initially be noticed that there is a tendency for individuals with explicit perceptions of the intentionality of criminals to be less punitive (although given the interactive design, the exact effect depends on the values on the emotion items). This effect appears because more individuals with explicit perceptions are explicit in the direction of perceiving criminals as having limited intentionality. ${ }^{5}$ Turning

\footnotetext{
${ }^{4}$ Note that this measure is reversed compared to the measure directly obtained using the revised Griffin formula.

${ }^{5}$ To illustrate the underlying distribution of this variable: of the respondents in the tertile with the most explicit perceptions, 70\% view criminals as more unintentional than intentional (i.e., have higher values on the scale measuring the former).
}

towards the interaction effects between the explicitness of the perceptions and the emotions of anger and compassion, we see that both-as hypothesizedare significant. When the explicitness of the perceptions of the intentionality of criminals increases, the influence of anger and compassion in the opinionformation process also increases. When the measure of the explicitness of the perception is at its maximum, the coefficient of anger is $-0.05+0.21=0.16$, and the coefficient of compassion is $0.07+-0.40=-0.33$. Hence, for this group, a change in emotional experience from low to high compassion towards criminals will bump the criminal justice attitude as much as $33 \%$ of the full scale in the direction of rejecting punishment. When the measure of the explicitness of the stereotype equals 0 , the effect of anger is statistically indistinguishable from 0 , while compassion has a significant but negligible effect in the counterintuitive direction (cf. the main terms). The influence of the interaction terms is, in other words, quite substantial and supports the anger-interaction and compassioninteraction hypotheses. Those who unambiguously perceive criminals as either accidental victims of social injustice or as intentional wrongdoers are thus provided with considerable emotional input when forming opinions on criminal justice issues. With respect to anxiety, the interaction effect is not significant. This supports the anxiety-no-interaction and shows that anxiety-laden opinions are not facilitated by perceptions of the intentionality of criminals. ${ }^{6}$

\section{Discussion}

Huddy, Feldman, and Cassese end their investigation of the distinct political effects of anger and anxiety by calling for "more research [... ] to explain why anger and anxiety are so closely associated in self-report data yet have such distinct consequences" (2007, 230). By providing a deeper understanding of anger and anxiety, the arguments and findings presented in this article

\footnotetext{
${ }^{6}$ The analysis in Table 1 includes the explicitness of the respondents' perceptions of criminal intent. One could also control for the actual content of these perceptions (i.e., whether criminals are perceived as intentional or unintentional wrongdoers). Based on the four items described in the design section, a simple additive scale was constructed. This measure ranges from the perception that most criminals are motivated by bad intentions to the perception that most criminals are accidental victims themselves at the other extreme. Importantly, the control for this measure does not substantially change the presented results. The interactions with anger and compassion remain significant, while the interaction with anxiety stays insignificant.
} 
TABLe 1 The Interaction of Emotions and Perceptions of Criminal Intentionality as Predictors of Criminal Justice Opinions. With Controls

\begin{tabular}{|c|c|c|}
\hline & Model 1 & Model 2 \\
\hline Constant & $0.49^{* * *}(0.01)$ & $0.58^{\star \star \star}(0.03)$ \\
\hline Gender (female) & $-0.01^{\star}(0.01)$ & $-0.01^{\star}(0.004)$ \\
\hline Age & $-0.01(0.01)$ & $-0.01(0.01)$ \\
\hline Education (high school) & $-0.04^{\star \star \star}(0.01)$ & $-0.04^{\star \star \star}(0.01)$ \\
\hline Anger & $0.08^{\star \star *}(0.01)$ & $-0.05(0.03)$ \\
\hline Compassion & $-0.19^{\star * \star}(0.01)$ & $0.07^{\star}(0.03)$ \\
\hline Anxiety & $0.06^{\star * *}(0.01)$ & $0.01(0.03)$ \\
\hline $\begin{array}{l}\text { Explicitness of perceptions of } \\
\text { the intentionality of criminals }\end{array}$ & - & $-0.14^{\star \star}(0.05)$ \\
\hline Explicitness of perceptions ${ }^{\star}$ Anger & - & $0.21^{* * *}(0.06)$ \\
\hline Explicitness of perceptions ${ }^{*}$ Compassion & - & $-0.40^{\star * *}(0.04)$ \\
\hline Explicitness of perceptions ${ }^{*}$ Anxiety & - & $0.07(0.04)$ \\
\hline $\mathrm{R}^{2}$ (adj.) & 0.28 & 0.31 \\
\hline
\end{tabular}

Note. $\mathrm{N}=3171$. Entries are unstandardized OLS regression coefficients, standard errors in parentheses. A high value on the dependent variable indicates support for punishment. All variables vary between 0 and $1 .{ }^{\star} \mathrm{p}<0.05^{\star *} \mathrm{p}<0.01{ }^{\star * *} \mathrm{p}<0.001$.

provide a solution to this puzzle. As will be recalled, previous research demonstrates that anger motivates an individual to approach the target of the emotion (i.e., go to war against Iraq) and facilitates optimistic assessments of the associated risks, while anxiety motivates one to avoid the target and facilitates pessimistic risk assessments. These differences are highly congruent with the present argument that anger is specifically designed to motivate the punishment of intentional rule violators. Approach is necessary for revenge seeking and, as also suggested by Druckman and McDermott $(2008,317)$, the optimism triggered by anger could be an evolved design feature of a motivational system designed to ensure that potentially costly revenge is indeed carried out. At the same time, this argument allows feelings of anger and anxiety to be highly correlated. Hence, intentional rule-violation is almost per definition hazardous, which also requires precautionary activity (if not before, then after revenge has been sought).

The findings of this study carry general implications for the scope of research on emotions in politics. Hence, they demonstrate the fruitfulness of distinguishing emotions beyond their valence. The present findings suggest that anger is not necessarily triggered by a deep sense of risk but rather by the moral evaluations of others. In this particular respect, anger resembles compassion rather than anxiety despite the fact that anger and anxiety have similar valence. This observation also nuances the distinctions between anger and anxiety made in some previous studies. Most notably, Affective Intelligence Theory suggests that while anxiety is activated by novel threats, anger is activated in the face of recurrent threat (Marcus, Neuman, and MacKuen 2000, 158; Marcus et al. 2006). The current findings, however, suggest that anger is not designed to process generic hazards, instead only influencing opinion in the face of negative events within the moral domain, i.e., when others have intentionally caused the event (see also Steenbergen and Ellis 2003). In other words, more than just being distinct from one another, anger and anxiety operate in distinct domains.

In a related vein, the present findings suggest that it is fruitful to pay greater attention to moral emotions. Hence, much prior research has focused on anxiety as the paradigmatic negative political emotion. Nevertheless, while politics is surely about the management of crises and threats, it is equally about moral issues such as the character of politicians and the deservingness of those affected by policies (Lakoff 1996). Specifically, the findings on anger and compassion link the literature on emotions in politics and the classic literature on policy opinions and perceptions. This literature has provided evidence that perceptions of the intentions and motivations of target groups such as welfare recipients, criminals, and immigrants strongly affect opinions on relevant issues (e.g., Gilens 1999; Iyengar 1991), and the present findings suggest that these perceptions (at least in part) are so compelling because they fit the trigger conditions of the emotions designed to pass moral praise and blame. The relevance of this observation even extends to other areas of public opinion such as candidate evaluation. Hence, the present findings corroborate the Steenbergen and Ellis (2006) conclusion that the 
existence of political problems only facilitates anger towards political candidates if these candidates can be held responsible in relation to the problems. In sum, then, the fit between perceptions of intentionality and moral emotions suggests that moral emotions are particularly important ingredients in the opinion formation of citizens.

These findings not only carry implications for our understanding of the emotional life of citizens, but also for our understanding of the communication of political elites. Hence, research has demonstrated that political elites use issue framing as a key strategic tool to shape how citizens think about issues (Chong and Druckman 2007), and recent arguments suggest that emotional appeals offer an important framing device (e.g., Gross 2008). Importantly, the present findings provide new perspectives on the political uses of anxiety appeals. Hence, while previous studies have associated anxiety proneness and conservatism (Oxley et al. 2008), the present findings suggest that the activation of anxiety is unconditioned by one important determinant of conservatism, namely perceiving others as intentional (Zucker and Weiner 1993). This lack of a fit between perceptions of intentionality and anxiety is central, because it suggests that elites across the political spectrum can effectively use anxiety and fear to direct public awareness to immanent political problems. For example, liberals can use anxiety appeals to direct attention to rising crime rates while simultaneously framing the crime in a manner inviting solutions focusing on the external causes of these problems (i.e., solutions premised on the lack of criminal intent).

More generally, the existence of distinct emotional systems entails both potentials and pitfalls for political elites. Hence, the existence of multiple emotions with distinct triggers and effects suggests that political elites can use issue framing to target highly specific emotions and, hence, trigger the effects best suited to persuade the electorate. At the same time, however, such targeting is difficult due to the importance of the fit between the cues provided by the frames and the relevant emotional systems. Hence, until now, research has provided little guidance as to which political cues trigger which emotions.

The present article suggests that evolutionary psychology provides a fruitful approach to the further mapping of the fit between political cues and emotional systems. In this way, this study adds to an increasing trend in political science involving the use of insights from evolutionary psychology to gain leverage in the understanding of political phenomena (see Hibbing and Smith 2007; Petersen 2009). While the current study does not provide conclusive evi- dence regarding the importance of evolutionary psychology to the study of political emotions, the evolutionary interpretation of the predicted effects is consistent with rather stunning evidence. This includes detailed experiments demonstrating that even nonhuman primates respond to social actions based on the intent behind the action (Hauser et al. 2003); the existence of specialized circuits in the human brain that are designed to process intentions (Baron-Cohen 1995); and the robust finding that these circuits are activated in situations of rule violation (for a review, see Petersen, Roepstorff, and Serritzlew 2009). If the evolutionary interpretation is indeed correct, it opens a number of interesting perspectives. Hence, research in evolutionary psychology suggests that our emotions were designed to enable ancestral humans to navigate adaptively in small-scale environments (Cosmides and Tooby 2006) and, specifically, that anger and compassion are regulated by cues of intentionality due to the adaptive value of discriminating between intentional and accidental wrongdoers in face-to-face-interaction. In this perspective, the present findings suggest that emotions facilitate opinion formation on modern political issues if, and only if, citizens perceive these issues in a way resembling ancestrally significant themes. Seemingly, the natural domain of the moral emotions of citizens is small-scale-not large-scale-politics.

\section{Acknowledgments}

The author wishes to thank Jamie Druckman, Rose McDermott, Martin Rosema, Svend-Erik Skaaning, Rune Slothuus and Lise Togeby for their helpful advice and suggestions.

Manuscript submitted 23 July 2008

Manuscript accepted for publication 6 July 2009

\section{References}

Axelrod, Robert. 1984. The Evolution of Cooperation. New York: Basic Books.

Barkow, Jerome, Leda Cosmides, and John Tooby. 1992. The Adapted Mind. New York and Oxford: Oxford University Press.

Baron-Cohen, Simon. 1995. Mindblindness. Cambridge, MA: The MIT Press.

Boyer, Pascal, and Pierre Liénard. 2006. "Why Ritualized Behavior? Precaution Systems and Action Parsing in Developmental, Pathological and Cultural rituals." Behavioral and Brain Sciences 29: 595-613.

Brader, Ted, Nicholas Valentino, and Elizabeth Suhay. 2008. "What Triggers Public Opposition to Immigration? Anxiety, 
Group Cues, and Immigration Threat." American Journal of Political Science 52: 959-78.

Chong, Dennis, and James Druckman. 2007. "Framing Theory." Annual Review of Political Science 10: 103-26.

Cosmides, Leda, and John Tooby. 2005. "Neurocognitive Adaptations Designed for Social Exchange." In Handbook of Evolutionary Psychology, ed. David Buss. Hoboken, NJ: John Wiley \& Sons, 584-627.

Cosmides, Leda, and John Tooby. 2006. "Evolutionary Psychology, Moral Heuristics, and The Law." In Heuristics and the Law, ed. Gert Gigerenzer and Christoph Engel. Cambridge: MIT Press, 182-212.

Cullen, Francis, Gregory Clark, John Cullen, and Richard Mathers. 1985. "Attribution, Salience, and Attitudes Toward Criminal Sanctioning." Criminal Justice and Behavior 12 (3): 305-31.

Damasio, Antonio. 2003. Looking for Spinoza. London: Vintage.

de Quervain, Dominique J. F., Urs Fischbacher, Valerie Treyer, Melanie Schellhammer, Schnyder Ulrich, Alfred Buck, and Ernst Fehr. 2004. "The Neural Basis of Altruistic Punishment." Science 305: 1254-58.

de Waal, Frans. 1996. Good Natured. The Origins of Right and Wrong in Humans and Other Animals. Cambridge, MA: Harvard University Press.

Druckman, James, and Rose McDermott. 2008. "Emotion and the Framing of Risky Choice." Political Behavior 30: 297-321.

Ellsworth, Phoebe C., and Klaus R. Scherer. 2003. "Appraisal Processes in Emotion." In Handbook of Affective Sciences, ed. Richard Davidson, Klaus Scherer and H. Hill Goldsmith. Oxford: Oxford University Press, 575-95.

Ellsworth, Phoebe C., and Craig A. Smith. 1988. "From Appraisal to Emotion: Differences Among Unpleasant Feelings." Motivation and Emotion 12: 271-302.

Ermer, Elsa, Scott Guerin, Leda Cosmides, John Tooby, and Michael Miller. 2006. "Theory of Mind Broad and Narrow." Social Neuroscience 1: 196-219.

Fiddick, Larry. 2004. "Domains of Deontic Reasoning." Quarterly Journal of Experimental Psychology 57A: 447-74.

Gault, Barbara, and John Sabini. 2000. "The Roles of Empathy, Anger and Gender in Predicting Attitudes toward Punitive, Reparative, and Preventative Public Policies." Cognition and Emotion 14 (4): 495-520.

Gilens, Martin. 1999. Why Americans Hate Welfare. Chicago and London: The University of Chicago Press.

Gross, Kimberly. 2008. "Framing Persuasive Appeals: Episodic and Thematic Framing, Emotional Response, and Policy Opinion." Political Psychology 29: 169-92.

Haidt, Jonathan. 2003. "The Moral Emotions." In Handbook of Affective Sciences, ed. Richard Davidson, Klaus Scherer, and H. Hill Goldsmith. Oxford: Oxford University Press, 852-70.

Hauser, Marc, M. Keith Chen, Frances Chen, and Emmeline Chuang. 2003. "Give unto Others: Genetically Unrelated Cotton-top Tamarin Monkeys Preferentially Give Food to Those Who Altruistically Give Food Back." Proceedings of the Royal Society, Biological Sciences 270: 2363-70.

Hibbing, J. R., and K. B. Smith. 2007. "The Biology of Political Behavior: An introduction." The ANNALS of the American Academy of Political and Social Science 614: 6-14.

Huddy, Leonie, Stanley Feldman, and Erin Cassese. 2007. "On the Distinct Poltical Effects of Anger and Anxiety." In The Affect Effect, ed. Russell Neumann, George Marcus, Ann Crigler and Michael MacKuen. Cambridge: Cambridge University Press, 202-30.
Iyengar, Shanto. 1991. Is Anyone Responsible? How Television Frames Political Issues. Chicago and London: The University of Chicago Press.

Keltner, Dacher, Phoebe Ellsworth, and Kari Edwards. 1993. "Beyond Simple Pessimism: Effects of Sadness and Anger on Social Perception." Journal of Personality and Social Psychology 64: 740-52.

Kuklinski, James H., Ellen Riggle, Victor Ottati, Norbert Schwarz, and Robert S. Wyer. 1991. "The Cognitive and Affective Bases of Political Tolerance Judgments." American Journal of Political Science 35: 1-27.

Lakoff, George. 1996. Moral Politics. Chicago and London: The University of Chicago Press.

Lazarus, Richard S. 1991. Emotion and Adaptation. New York: Oxford University Press.

Lodge, Milton, and Charles S. Taber. 2005. "The Automaticity of Affect for Political Leaders, Groups, and Issues: An Experimental Test of the Hot Cognition Hypothesis." Political Psychology 26: 455-82.

Marcus, George E. 2002. The Sentimental Citizen. University Park: The Pennsylvania State University Press.

Marcus, George, Michael MacKuen, Jennifer Wolak, and Luke Keele. 2006. "The Measure and Mismeasure of Emotion." In Feeling Politics, ed. David P. Redlawsk. New York: Palgrave MacMillan Publishing, 31-46.

Marcus, George, Russell Neuman, and Michael MacKuen. 2000. Affective Intelligence and Political Judgment. Chicago and London: The University of Chicago Press.

Neumann, Russell, George Marcus, Ann Crigler, and Michael MacKuen. 2007. The Affect Effect. Cambridge: Cambrige University Press.

Niedenthal, Paul, and Marc Setterlund. 1994. "Emotion Congruence in Perception." Personality and Social Psychology Bulletin 20: 401-10.

Oxley, Douglas, Kevin Smith, John Alford, Matthew Hibbing, Jennifer Miller, Mario Scalora, Peter Hatemi, and John Hibbing. 2008. "Political Attitudes Vary with Physiological Traits." Science 321: 1667-70.

Petersen, Michael Bang. 2009. "Public Opinion and Evolved Heuristics: The Role of Category-Based Inference.” Journal of Cognition and Culture, 9: 367-89.

Petersen, Michael Bang, Andreas Roepstorff, and Søren Serritzlew. 2009. "Social capital in the brain?" In Handbook of Social Capital, ed. Gert T. Svendsen and Gunnar L. H. Svendsen. Northampton, MA: Edward Elgar Publishing, 75-92.

Petersen, Michael Bang, Aaron Sell, John Tooby, and Leda Cosmides. 2010. "Evolutionary Psychology and Criminal Justice: A Recalibrational Theory of Punishment and Reconciliation." In Human Morality and Sociality. Evolutionary and Comparative Perspectives, ed. Henrik Høgh-Olesen. Hampshire: Palgrave Macmillan, 72-131.

Redlawsk, David P. 2006. Feeling Politics. New York: Palgrave MacMillan Publishing.

Redlawsk, David P., Andrew J. W. Civettini, and Richard R. Lau. 2007. "Affective Intelligence and Voting: Information Processing and Learning in a Campaign." In The Affect Effect, Russell Neumann, George Marcus, Ann Crigler, and Michael MacKuen. Cambridge: Cambridge University Press, 152-79.

Sanfey, Alan G., James K. Rilling, Jessica A. Aronson, Leigh E. Nystrom, and Jonathan D. Cohen. 2003. "The Neural Basis of Economic Decision-Making in the Ultimatum Game.” Science 300: 1755-58. 
Smith, Craig A., and Phoebe C. Ellsworth. 1985. "Patterns of Cognitive Appraisal in Emotion." Journal of Personality and Social Psychology 48 (4): 813-38.

Smith, Craig A., Kelly H. Haynes, Richard S. Lazarus, and Lois K. Pope. 1993. "In Search of the 'Hot' Cognitions: Attributions, Appraisals and Their relation to Emotion." Journal of Personality and Social Psychology 65: 916-29.

Sniderman, Paul M., Richard A. Brody, and Philip E. Tetlock. 1991. Reasoning and Choice. Explorations in Political Psychology. Cambridge and New York: Cambridge University Press.

Sprott, Jane, and Anthony Doob. 1997. "Fear, Victimization, and Attitudes to Sentencing, the Courts, and the Police." Canadian Journal of Criminology 39: 275-91.

Steenbergen, Marco, and Paul Brewer. 2004. "The Not-SoAmbivalent Public: Policy Attitudes in the Political Culture of Ambivalence." In Studies in Public Opinion, ed. Willem E. Saris and Paul M. Sniderman. Princeton: Princeton University Press, 93-129.

Steenbergen, Marcu, and Christopher Ellis. 2006. "Fear and Loathing in American Elections: Context, Traits, and Negative Candidate Affect." In Feeling Politics, ed. David P. Redlawsk. New York: Palgrave MacMillan Publishing, 109-33.
Stubager, Rune. 2008. "Education Effects on AuthoritarianLibertarian Values: A Question of Socialization." The British Journal of Sociology 59: 327-50.

Tooby, John, Leda Cosmides, Aaron Sell, Debra Lieberman, and Daniel Sznycer. 2008. "Internal Regulatory Variables and the Design of Human Motivation: A Computational and Evolutionary Approach." In Handbook of Approach and Avoidance Motivation, ed. Andrew J. Elliot. Mahwah, NJ: Lawrence Erlbaum Associates, 251-71.

Weiner, Bernard. 1995. Judgments of Responsibility. New York and London: The Guilford Press.

Zucker, Gail Sahar, and Bernard Weiner. 1993. "Conservatism and Perceptions of Poverty: An Attributional Analysis." Journal of Applied Social Psychology 23: 925-43.

Michael Bang Petersen is Assistant Professor in Department of Political Science Aarhus University, Aarhus, Denmark. 